\title{
Dental Records and what they can Reveal about Tobacco Use Intervention Practices
}

\author{
M A Al-Kayyal' , N A Al-Hazmi
}

\begin{abstract}
INTRODUCTION Tobacco use prevention and cessation is a practice required by every dentist. It is a fundamental tenet in the fight against tobacco. Fundamentally, the first step of any tobacco use prevention practice includes the identification of tobacco users and a history of their habit. This information is recorded in the dental record of the patient and provides a baseline for the assessment and counseling of the patient in regards to their oral health.

OBJectives To investigate if tobacco use is regularly recorded in dental records of patients attending King Abdulaziz University Faculty of Dentistry (KAUFD).

METHODS Four hundred and ninety-four dental records were randomly sampled out of 31,323 records opened during the last three years. Dental records were assessed for information pertaining to the use of tobacco products, the type used, frequency and duration of tobacco use. RESULTS Only 364 dental records showed that tobacco use information was asked (73\%), and of these, only $2 \%$ were asked when they started, $4 \%$ were asked how often they use tobacco, and $16 \%$ were asked about the type of tobacco used. From the dental records sampled, the prevalence of tobacco use among the patients attending KAUFD during that period was $16 \%$. concLusions In regards to tobacco use, all patients must be asked if they use tobacco in any form. Tobacco habits not only cause systemic diseases, but have direct detrimental effects on the oral cavity and greatly deter dental treatment. Dental records provide an excellent source of information for institutes and clinical offices, to monitor the practice of tobacco use prevention and cessation in its simplest terms.
\end{abstract}

\section{AFFILIATION}

1 Ministry of National GuardHealth Affairs, Jeddah, KSA

2 King Abdulaziz University

Faculty of Dentistry, Jeddah, Saudi Arabia

CORRESPONDENCE TO

N A Al-Hazmi. King Abdulaziz University Faculty of Dentistry, P.O. Box 80498, Jeddah 21589 Saudi Arabia. Email:

nalhazmi@kau.edu.sa.Phone number: +966506378349

\section{KEYWORDS}

Tobacco, tobacco use prevention and cessation, denta records, students

\section{INTRODUCTION}

Tobacco use and dependence is the leading cause of preventable premature death worldwide ${ }^{1}$, and it is a major cause of avoidable morbidity and mortality in the United States ${ }^{2}$. According to the World Health Organization (WHO), recent estimates indicate that there are more than 1 billion smokers throughout the world $^{3,4}$, exposing billions of non-smokers to second-hand smoke (SHS) ${ }^{5}$. To date, the use of tobacco is responsible for the deaths of 6 million people each year ${ }^{4}$, including more than 600,000 non-tobacco users who die from SHS ${ }^{4}$. In 2004, it was found that $30 \%$ to $35 \%$ of adults and $40 \%$ of children were found to have been exposed to $\mathrm{SHS}^{5,6}$. Most of the disease burden of SHS, as measured by disability-adjusted life years, is experienced by children (61\%), followed by women (24\%) and men $(16 \%)^{6,7}$. The proportion of deaths attributed to SHS is $47 \%$ in women, $28 \%$ in children, and $26 \%$ in men ${ }^{6,7}$. It is well documented that smoking is not only a health burden but also costs the world billions of dollars each year ${ }^{4}$.

The oral cavity is the first area of the body affected by tobacco products ${ }^{8,9}$. Tobacco use impacts many oral conditions, including dental caries, periodontal diseases, oral cancer, impaired wound healing, reduced ability to smell and taste, staining of the teeth, leukoplakia, oral precancerous lesions, halitosis and implant failure ${ }^{9-12}$. Tobacco-using patients have a $21 \%$ risk of crown and root caries, which is double that of previous users and never-users $(10 \%)^{9}$. Furthermore, $20 \%$ 
of periodontal disease is attributed to tobacco use, and the severity of periodontal disease is directly related to the amount of tobacco used ${ }^{9}$. Head and neck squamous cell carcinoma, with an annual incidence of more than 500,000 cases, is another possible consequence of tobacco use, particularly if tobacco is chewed (smokeless tobacco use) $)^{13,14}$. The oral cancer risk in smokers is 3.43 times higher than in non-tobacco-users, and the increase in risk is dose-dependent ${ }^{15,16}$. The risk for oral cancer and periodontal disease of smokers returns to normal after ten years of smoking cessation ${ }^{15}$.

Saudi Arabia ranks 4th worldwide in the import of tobacco products ${ }^{17}{ }^{18}$. The $\mathrm{WHO}$ estimated the prevalence of smoking to be $17.1 \%$ among adults in $2015^{4}$ and $14.9 \%$ of children and youth were found to be smokers in $2010^{19}$. Because dental visits provide a unique base for successful tobacco use intervention, dentists, as health care providers, may play a significant role in the fight against tobacco use ${ }^{12}$. Previous studies have shown that oral health care providers are acutely cognizant of the negative impacts of tobacco use habits ${ }^{12}$.However, tobacco use intervention by dental care providers, compared to other health care providers, ranked the lowest, both in number and effectiveness worldwide ${ }^{10}$. Based on such findings, the WHO Global Oral Health Program recognized the implementation of tobacco use prevention and cessation (TUPAC) counseling guidelines to be of vital and essential importance in dentistry ${ }^{20}$. In March 2002, the International Association for Dental Research (IADR), during an ad-hoc Committee on Tobacco meeting, specified that the important role dentists and hygienists should play in tobacco use prevention should be highlighted ${ }^{21}$. This was further emphasized by the WHO, which stated that this tobacco use counseling should become an essential tenet of the dental curriculum ${ }^{22}$.

Various models of TUPAC have been adopted by the WHO, World Dental Federation, and the IADR ${ }^{23}$. They include the 3As (Figure 1), 4As, 5As, and 5Rs ${ }^{2,24}$. During the Second European Workshop on Tobacco Use Prevention and Cessation for Oral Health Professionals held in Zagreb, Croatia in 2008, a consensus report on TUPAC was drafted, proposing four stages for tobacco use intervention ${ }^{15,24}$. Stage 1, Basic Care, included identification and documentation of patients' tobacco habits in their medical records; Stage 2, Further Basic Care, consisted of brief intervention; Stage 3, Intermediate Care and Stage 4, Advanced Care, included more extensive intervention, including motivational interviewing ${ }^{15}$. These levels of approach give clinicians the freedom to offer tobacco counseling services that best suit them and their patients ${ }^{24}$. In this context, dental schools, as the primary source of education for dental professionals, should be viewed as the nucleus of effective tobacco-use intervention programs ${ }^{25}$.

\section{METHODS}

Patients attending KAUFD are registered and a dental record is created for each one. Dental Records have historically been paper-based and this has changed to electronic records in the past few years. In this study, the total number of dental records opened during the year was recorded and the sample size was determined using an online sample size calculator (Creative Research Systems ${ }^{\circledR}$ ). This gave us the number of records to be sampled that would represent the total number opened during the year. Randomization of the sample was as follows: Sample "0" (S0) was the first dental record opened on January 1st 2013. A dental record was withdrawn every 10 dental records opened sequentially. Records were eligible only if the patient was aged 17 years or more. Maintaining a confidence level of $95 \%$ and a significance level of $5 \%$, a minimum of 380 records would be representative for our study (http://www.surveysystem.com/sscalc.htm.). A final number of four hundred forty-nine dental records were included in this study.

An audit form was designed, which included:

- Dental record number

- Date the dental record was opened

- Patient's age and sex

- Name/job description of the screening dentist

- Tobacco-related information

- Name of the treating dentist and his status (student, intern, faculty). Screening and treating dentists were classified as Student, Intern, General Practitioner (GP), or Faculty.

Audits were carried out in the Dental Records Office of KAUFD after working hours to avoid hampering the work flow of the institute (5pm until 8pm).

The tobacco information was audited to assess whether Stage 1, Basic Intervention, was carried out ${ }^{15}$, including asking and documenting the four questions of the 1st "A" (Ask) of the Basic Model, "AAR" (Figure 1). The four questions were: 'Do you use any tobacco products?'; 'What type of tobacco do you use?'; 'Since when have you been using the tobacco products?; and 'How often do you use the tobacco product?' Three dentists carried out the auditing after calibration.

Data was entered, and analysis was performed using Statistical Package for Social Science (SPSS Inc., Chicago, IL, USA) version 18 software. Descriptive summaries were completed for all items on the audit form. Further calculations were performed to correlate the questions asked with the clinician. 
Figure 1. The 3As Model (Ask-Advise-Arrange(Refer))
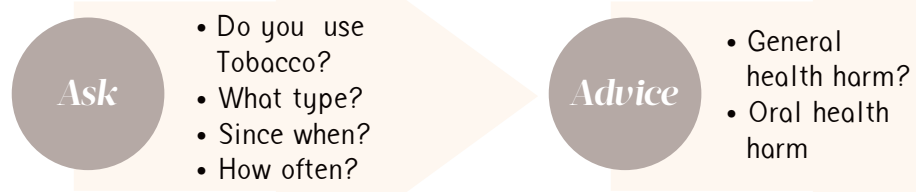

Figure 2. Graph showing the distribution of individuals who carried out the screening.

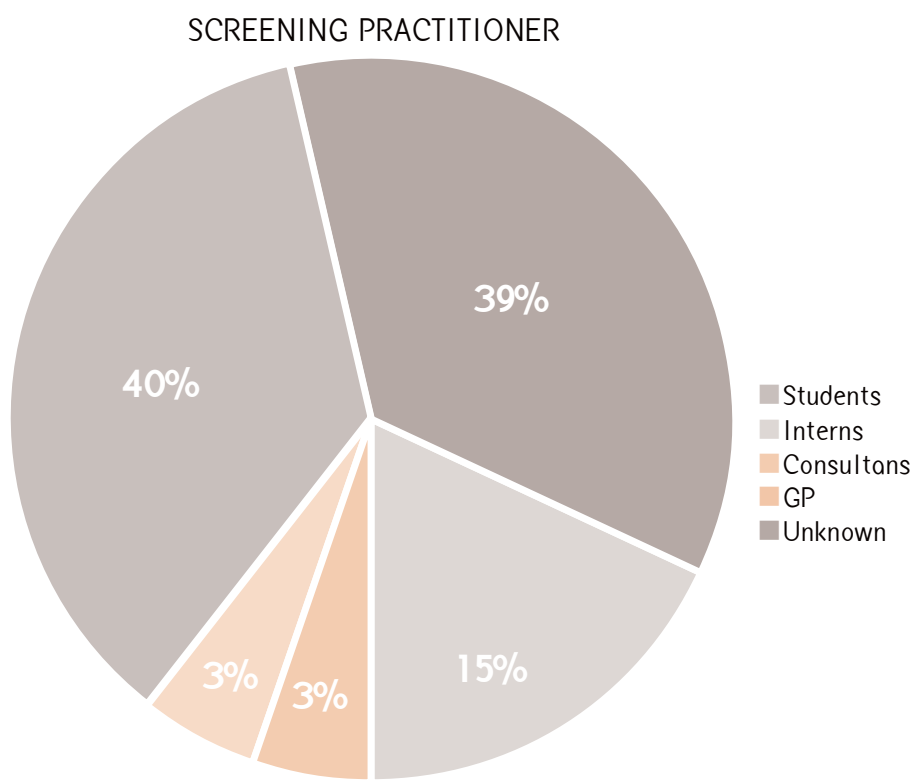

Figure 3. Sample of patients asked about their tobacco use habits

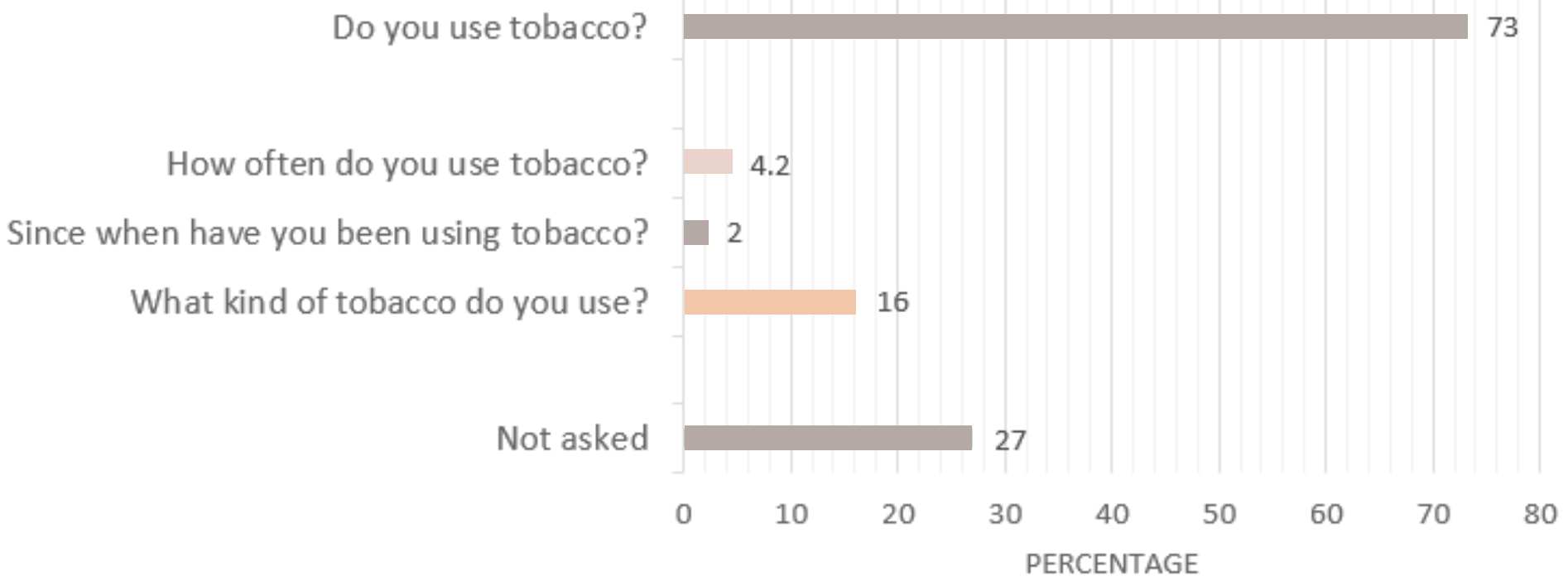

\section{RESULTS}

Of the 494 patients whose dental records were included, $44 \%$ were male $(n=217)$ and $66 \%$ females $(n=281)$. Age ranged from 17 years to 60 years (mean was 35.32 years). In addition, $191(38.7 \%)$ of the patients were screened by students, 74 (15\%) by interns, 15 (3\%) by faculty members, and $14(2.8 \%)$ by GPs. The screening clinician of the remaining 200 (40.5\%) could not be identified (Figure 2).

Three-hundred and sixty-four patients (73.7\%) were asked whether they used tobacco ( $\mathrm{n}$ tobacco-use $=364$ ); however, of those asked, only 58 (16\%) were further asked what type, 7 $(2 \%)$ were asked since when, and 15 (4.2\%) were asked how often (Figure 3). As shown in Figure 4, of the patients who were asked (n tobacco-use $=364), 93(25.5 \%)$ were asked by students, 47 (13\%) by interns, 7 (2\%) by faculty members, and $4(1.2 \%)$ by GPs. However, $213(58.3 \%)$ of these records did not identify the practitioner who opened the file. The prevalence of tobacco use among those who were asked was $16 \%$ (n smokers $=58$ ) (Figure 5), of which 38 (66\%) were between the ages of 18-45. Of those who were further asked what type, 26 (44.3\%) answered "cigarettes" (Figure 6). 
Figure 4. Practitioner who asked about tobacco use.

30

25

20

$25.5 \%$

15

10

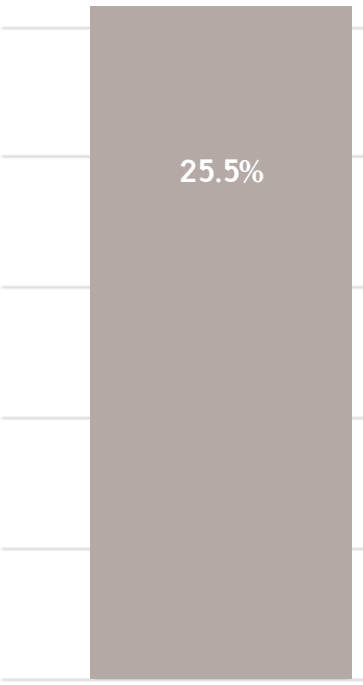

Students

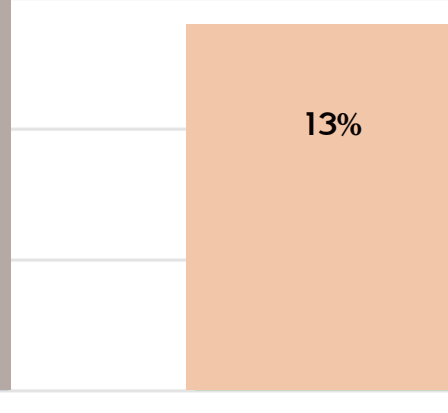

Interns

$2 \%$

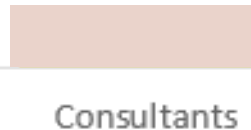

Consultants
$1.2 \%$

GP

Figure 5. Prevalence of smokers out of the sample that were asked about tobacco use (73\%).

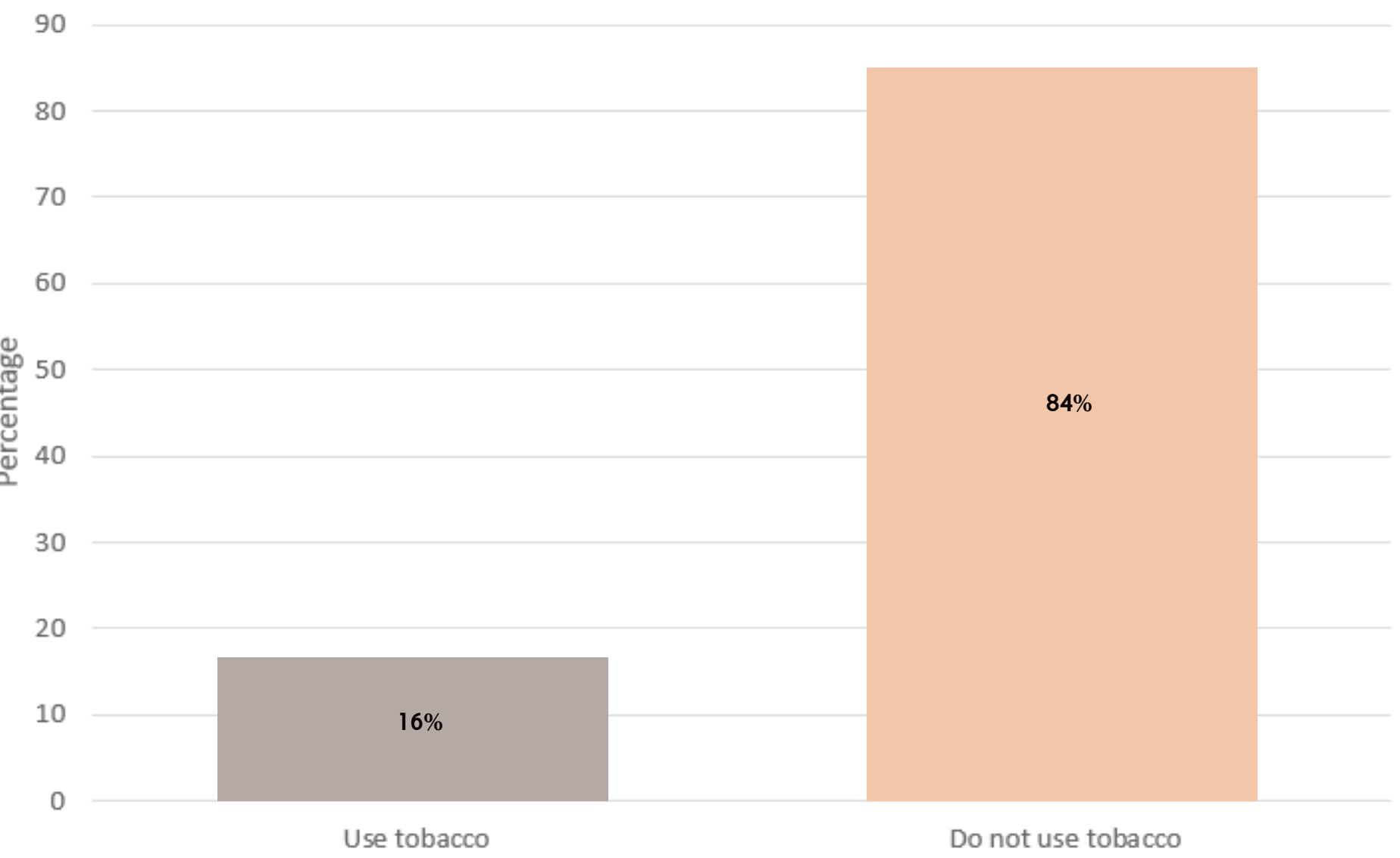




\section{Figure 6. Of the 16\% that were asked whether or not they used tobacco, when asked what type, the answered varied from cigarette to hubbly bubbly to smokeless tobacco.}

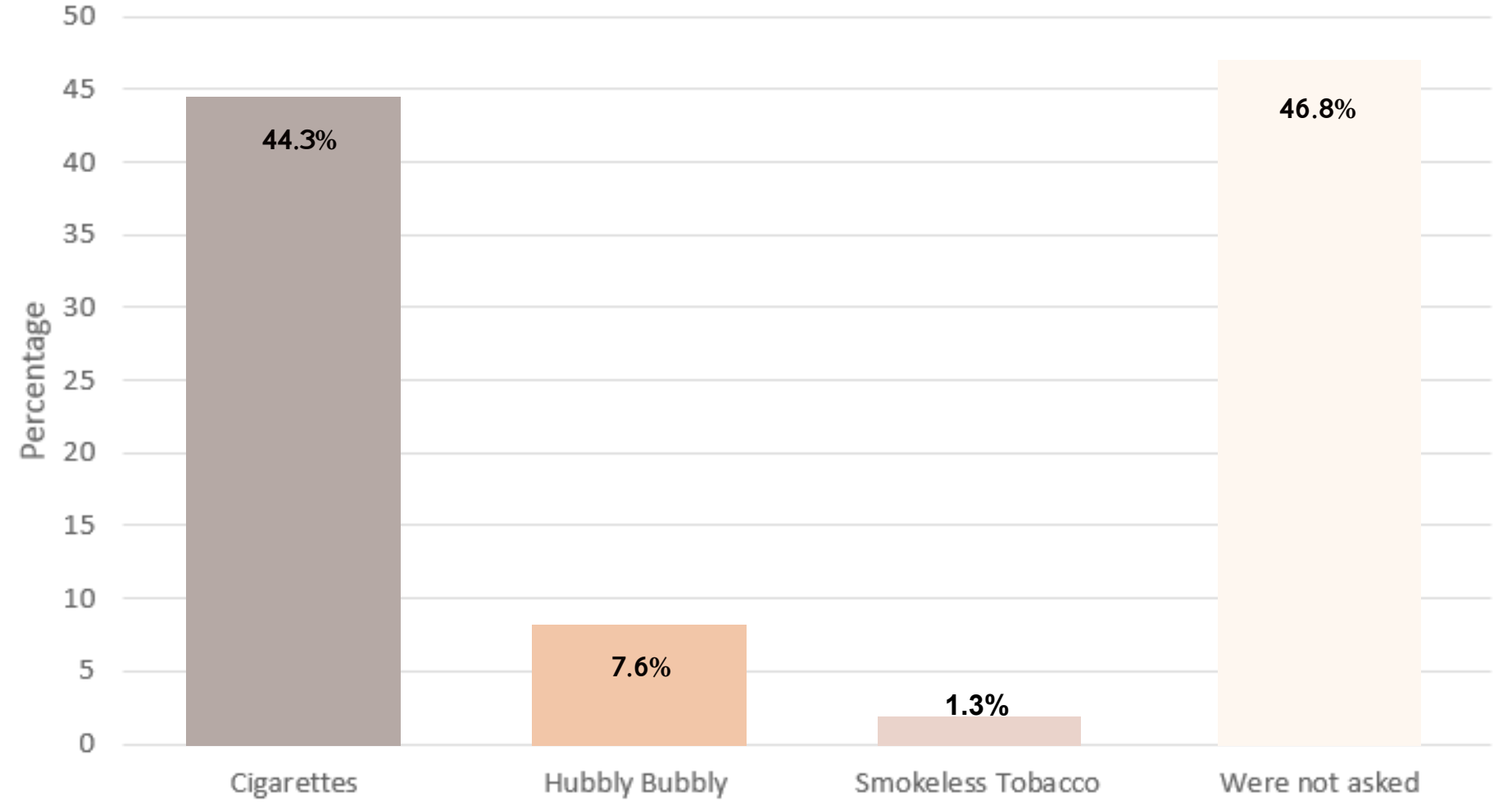

\section{DISCUSSION}

This study shows that most of the patients at KAUFD are asked whether they use tobacco or tobacco products (73.7\%). However, further details about such use were not acquired from most of them. This finding reflects that most of our dental practitioners are indeed aware of their duty to inquire about tobacco habits as part of the 'risk factors to oral health,' but did not feel compelled to take it further than the first question. Dental students and interns were the most likely clinicians to ask about tobacco use (25.5\% and $13 \%$, respectively). This is similar to finding by Uti and Sofola (2011) who found that students were more likely than dentists to ask their patients about their tobacco use habits ${ }^{26}$. In a study conducted in a single dental school in the UK, $94 \%$ of the students did record their patients' tobacco habits in their charts ${ }^{16}$. In the US, the percentage of dentists who ask their patients is much lower, between $30 \%$ and $50 \%{ }^{10,11,25}$. It was surprising that faculty members showed less responsibility than their students in this regard, but a conclusive statement cannot be made, because $40 \%$ of the records failed to identify the screening dentist. However, the conclusion that among the $40 \%$, the likely screening dentists were staff and not students can be made because all students working on cases must provide proof that the patient was being treated by them. This makes the signing of their name and personal identification number a mandatory step in the education process.

Overall, however, the practice of tobacco use history-taking among all practitioners is low. This is alarming, because studies have shown that health care providers are more likely to provide tobacco use intervention when they indicate their patients' habits on their charts ${ }^{25}$.

In our study, we found that two-thirds (66\%) of the tobacco users ranged between the ages of 18 and 45 years. This agrees with previous evidence suggesting that most smokers visit dental offices at an early age, during which intervention may significantly affect the long-term occurrence of tobacco-use comorbidities ${ }^{10,24}$. The available data has shown that the dental team is in a favorable position for such intervention ${ }^{10,15,27,28}$. More than $50 \%$ of smokers make annual visits to their dentists and are usually seen by the same dentist, which increases the opportunity for establishing a positive rapport between dentist and patient ${ }^{10-12,16,24,29}$. Because the effects of tobacco, such as aesthetic alteration, are more evident in the oral cavity than in other systems, it is more sensible that the dental office is the focus for effective tobacco use intervention practices ${ }^{8,10}$. Despite the fact that more advanced intervention has been proven to be more effective ${ }^{24}$, evidence has shown that even basic intervention with simple advice from any health care 
provider results in small but significant tobacco use cessation rates $^{1,8,24,30}$.

Our finding that $16 \%$ of Saudi patients attending KAUFD during that period were users of tobacco (smoked) agrees with the estimate by the $\mathrm{WHO}(17.1 \%)^{19}$. This makes it of paramount importance that further education and establishment of tobacco use intervention protocols be taught and applied. Our work has revealed that KAUFD is not diligent enough in this practice, and this could be the result of a lack of proper knowledge and training. Reports have shown that more than half of the US and less than two-thirds of the European dental schools provide tobacco-use intervention program courses ${ }^{11}$, and various methods of training highly improve the tobacco cessation intervention outcomes ${ }^{31}$.

The results presented here have provided a fundamental insight during the implementation of the new electronic health record system (EHR-R4) in the school. Medical history and risk assessment in the EHR-R4 are presented in the form of a check-list. It was suggested, and subsequently implemented, that the software require that either 'yes' or 'no' be indicated for each question at the time of history taking. A second audit of the electronic health records will provide insight into whether the practice of tobacco use history is carried out more frequently than when paper-based records are used.

Currently, Saudi Arabia has a total of sixteen dental schools; six of them are private, and the rest are governmental ${ }^{32}$. The results of this study cannot be generalized for all undergraduate dental programs in Saudi Arabia but does necessitate further investigations to include the majority of the dental schools nation-wide. The implementation of TUPAC by dental practitioners is not yet a fundamental parameter of competent dental practices in Saudi Arabia. Further education and implementation of, at the very least, Stage 1 basic intervention, is highly recommended; this would undoubtedly improve the service we provide our patients.

\section{CONCLUSION}

The education of dental graduates is one of the tenets in the fight against tobacco. It is not enough to teach students the didactic part of tobacco use prevention and cessation, but it is also important to ensure the continue the practice. As an educational institute, we have the ability to ensure this practice by integrating TUPAC in the curriculum and assigning to it the grading weight for the completion of clinical cases. However, without continuous monitoring, this will remain at best a sporadic practice particularly among nonstudents practicing in the dental school. Therefore, audits, which measure particular key performance indicators (KPIs) such as the implementation of TUPAC by all staff, can be used to evaluate the excellence of the institute in its commitment to benefiting the community.

\section{REFERENCES}

1. Frank E, Elon L, Spencer E. Personal and clinical tobacco-related practices and attitudes of U.S. medical students. Prev Med, 2009. 49(2-3): p. 233-9.

doi: 10.1016/j.ypmed.2009.06.020

2. Prakash P, Belek MG, Grimes B, et al., Dentists' attitudes, behaviors, and barriers related to tobacco-use cessation in the dental setting. J Public Health Dent, 2013. 73(2): p94-102. doi: 10.1111/j.17527325.2012.00347.x.

3. Tobacco - Fact sheet. Updated June 2016. Available at: http://www. who.int/mediacentre/factsheets/fs339/en/cited 2016 (accessed November 2016)

4. World Health Organization (2016). 2015 WHO report on the global tobacco epidemic, 2015: warning about the dangers of tobacco. Available at: http://whqlibdoc.who.int/ publications/2015/9789240687813_eng.pdf?ua=1. (accessed November 2016)

5. Wipfli HL, Samet JM, Second-hand smoke's worldwide disease toll. The Lancet, 2011. 377(9760): p101-02. doi: 10.1016/S0140-6736(10)61388-8.

6. Lubick N, Global estimate of SHS burden. Environ Health Perspect, 2011. 119(2): p66-7.

7. Öberg M, Jaakkola MS, Woodward A, et al., Worldwide burden of disease from exposure to second-hand smoke: a retrospective analysis of data from 192 countries. The Lancet, 2011, 377(9760): p139-46.

doi: 10.1016/S0140-6736(10)61388-8

8. Maillet JP, Tax CL, Neish NR, et al., Evaluation of outcomes for tobacco cessation counseling in the Dalhousie University dental hygiene curriculum. J Dent Educ, 2010. 74(3): p311-7.

9. Shibly O, Effect of tobacco counseling by dental students on patient quitting rate. J Dent Educ, 2010. 74(2): p140-8.

10. Albert D, Ward A, Ahluwalia K, et al., Addressing tobacco in managed care: a survey of dentists' knowledge, attitudes, and behaviors. Am J Public Health, 2002. 92(6): p997-1001.

11. Vered Y, Livny A, Zini A, et al., Dental students' attitudes and behavior toward smoking cessation as part of their professional education. Teach Learn Med, 2010. 22(4): p268-73

12. Amemori M, Michie S, Korhonen T, et al., Assessing implementation difficulties in tobacco use prevention and cessation counselling among dental providers. Implement Sci, 2011. 6: p50.

13. Warnakulasuriya S. Smokeless Tobacco and Oral Cancer. Oral Diseases, 2004. 10: p1-4.

14. Tovaru S, Mircea A, Update in stomatology: assuring dental student head and neck cancer screening competency. Maedica (Buchar), 2011. 6(2): p162-3.

15. Ramseier CA, Warnakulasuriya S, Needleman IG, et al., Consensus Report: 2nd European Workshop on Tobacco Use Prevention and Cessation for Oral Health Professionals. Int Dent J, 2010. 60(1): p3-6.

16. Clareboets S, Sivarajasingam V, Chestnutt IG, Smoking cessation advice: knowledge, attitude and practice among clinical dental students. Br Dent J, 2010. 208(4): p173-7. doi: 10.1038/sj.bdj.2010.158. 


\section{Research Paper}

17. Al Moamary MS, Tobacco consummation: Is it still a dilemma? Ann Thorac Med, 2010. 5(4): p193-4. doi: 10.4103/1817-1737.69103.

18. Salama R, Challenges facing smokers in Saudi Arabia. Int J Health Sci (Qassim), 2012. 6(2): pV-VI.

19. World Health Organization (2016). WHO Report on the Global Tobacco Epidemic, 2015, Country profile: Saudi Arabia. Available at: http://www.who.int/tobacco/surveillance/policy/country_profile/ sau.pdf. (accessed November 2016)

20. Petersen PE, World Health Organization global policy for improvement of oral health--World Health Assembly 2007. Int Dent J, 2008. 58(3): p115-21.

21. Greene JC, Tobacco use, prevention, and cessation: introduction to the special section. IADR Symposium on Tobacco Use, Prevention, and Cessation. J Dent Educ, 2002. 66(9): p1049-50.

22. Johnson NW, Bain CA, Tobacco and oral disease. EU-Working Group on Tobacco and Oral Health. Br Dent J, 2000. 189(4): p2006.

23. Ehizele AO, Azodo CC, Ezeja EB, et al., Nigerian dental students' compliance with the 4As approach to tobacco cessation. J Prev Med Hyg, 2011. 52(1): p12-6.

24. Davis JM, Ramseier CA, Mattheos N, Schoonheim-Klein M, Compton S, Al-Hazmi N, Polychronopoulou A, Suvan J, Antohé ME, Forna D, Radley N, Education of tobacco use prevention and cessation for dental professionals--a paradigm shift. Int Dent J, 2010. 60(1): p6072 .

25. Hennrikus D, Rindal DB, Boyle RG, et al., How well does the health history form identify adolescent smokers? J Am Dent Assoc, 2005. 136(8): p1113-20.

26. Uti OG, Sofola OO, Smoking Cessation Counseling in Dentistry: Attitudes of Nigerian Dentists and Dental Students. Journal of Dental Education, 2011. 75 (3): p406-412

27. Mohanty VR, Rajesh GR, Aruna DS, Role of Dental Institutions in Tobacco Cessation in India: Current Status and Future Prospects. Asian Pacific J Cancer Prev, 2013. 14(4): p2673-2680.

28. Cauchi D, Mamo J, Smoking Health Professional Student: An Attitudinal Challenge for Health Promotion? Int J Environ Res Public Health, 2012. 9: p2550-2561. doi: 10.3390/ijerph9072550.

29. Saito A, Nishina M, Murai K, et al., Health professional's perceptions of and potential barriers to smoking cessation care: a survey study at a dental school hospital in Japan. BMC Res Notes, 2010. 3: p329.

30. Gorin SS, Heck JE, Meta-analysis of the efficacy of tobacco counseling by health care providers. Cancer Epidemiol Biomarkers Prev, 2004. 13(12): p2012-22.

31. Walsh MM, Belek M, Prakash P, et al., The effect of training on the use of tobacco-use cessation guidelines in dental settings. J Am Dent Assoc, 2012. 143(6): p602-13.

32. Ministry of Education, Saudi Arabia (2016). Available at: http:// www.moe.gov.sa/ar/Pages/default.aspx. (accessed November 2016)

ACKNOWLEDGMENTS

The authors wish to acknowledge $\mathrm{Dr}$ Mohammad S Akel for his help during the project.

CONFLICT OF INTEREST

All the authors have completed and submitted the ICMUE Form for Disclosure of Potential Conflicts of Interest and none were reported.

FUNDING

There was no source of funding for this research.

PROVENANCE AND PEER REVIEW

Not commissioned;

Externally peer reviewed 